\title{
Silicon-based nanomaterials for lithium-ion batteries
}

\author{
YIN YaXia, WAN LiJun \& GUO YuGuo* \\ CAS Key Laboratory of Molecular Nanostructure and Nanotechnology, Institute of Chemistry, Chinese Academy of Sciences, \\ Beijing 100190, China
}

Received November 1, 2011; accepted December 22, 2011; published online March 31, 2012

\begin{abstract}
Silicon-based nanomaterials have been of scientific and commercial interest in lithium-ion batteries due to the low cost, low toxicity, and high specific capacity with an order of magnitude beyond that of conventional graphite. The poor capacity retention, caused by pulverization of Si during cycling, triggers researchers and engineers to explore better battery materials. This review summarizes recent work in improving Si-based anode materials via different approaches from diverse $\mathrm{Si}$ nanostructures, $\mathrm{Si} / \mathrm{metal}$ nanocomposites, to $\mathrm{Si} / \mathrm{C}$ nanocomposites, and also offers perspectives of the Si-based anode materials.
\end{abstract}

silicon, high energy density, nanomaterials, anode, lithium-ion batteries

Citation: $\quad$ Yin Y X, Wan L J, Guo Y G. Silicon-based nanomaterials for lithium-ion batteries. Chin Sci Bull, 2012, 57: 4104-4110, doi: 10.1007/s11434-012-5017-2

Lithium ion batteries (LIBs) as attractive energy storage devices have become ubiquitous power sources for mobile electronics. Increasing power and energy requirements for applications such as electric and hybrid electric vehicles, have spurred intense interest in developing high capacity electrode materials to surpass the capacities of electrode materials used in current LIBs [1-7]. To achieve the requirements, much research work has been performed on new anode materials with high specific capacities.

Silicon has attracted increasing attention as a potential high-capacity anode material because of numerous appealing features such as high theoretical specific capacity of $4212 \mathrm{mAh} \mathrm{g}^{-1}$, higher safety and stability than graphite (lithiated silicon is more stable in typical electrolytes than lithiated graphite). Si anode materials, however, suffer from some drawbacks involving the drastic volume change (larger than 300\%) during the alloying/de-alloying reactions with $\mathrm{Li}$ [8], the intrinsic low electrical conductivity, and the unstable solid electrolyte interphase (SEI) formed in the common electrolyte of $\mathrm{LiPF}_{6}$. These limitations still challenge the investigation and development on identification of higher capacity for the next generation LIBs. Various ad-

\footnotetext{
*Corresponding author (email: ygguo@iccas.ac.cn)
}

vances in Si morphology have been achieved in the past years, demonstrating that nanostructured Si-based materials particularly offer superior properties in LIBs.

In this review, we address the recent developments in optimizing Si-based materials via diverse $\mathrm{Si}$ nanostructures, $\mathrm{Si} /$ metal nanocomposites, and $\mathrm{Si} / \mathrm{C}$ nanocomposites. In addition, we offer some perspectives for the design of better $\mathrm{Si}$ nanomaterials.

\section{Si nanostructures}

In principle, Si-based bulk materials exhibited a marked loss of capacity in a few cycles. To alleviate the absolute volume variation during cycling, diverse Si nanostructures have been developed. It has been demonstrated that $\mathrm{Si}$ nano-powder $(78 \mathrm{~nm})$ could exhibit a better capacity retention than the commercial Si powder (250 mesh) [9]. The improvement was assigned to the shortening of lithium ion diffusion distance and enhancing the electroactivity toward Li uptake/release.

Controlling the nanoparticle shape as well as size can offer advantages, which is illustrated by recent results on different morphologies of Si. Zero-dimensional (OD) Si nano- 
spheres were constructed with enhanced electrochemical performances due to preventing Si particles' aggregation on the nanometer scale. Nest-like Si nanospheres prepared by a modified solvothermal method exhibited a large specific capacity of $3052 \mathrm{mAh} \mathrm{g}^{-1}$ under a current density of 2000 $\mathrm{mA} \mathrm{g}^{-1}$ (ca. $0.5 \mathrm{C}$ ) in the electrolyte of $1 \mathrm{~mol} / \mathrm{L} \mathrm{LiPF}_{6}$ dissolved in a 3:1:1 mixture of ethylene carbonate (EC), propylene carbonate (PC) and diethyl carbonate (DEC) [10]. After cycling of up to 48 cycles under $2000 \mathrm{~mA} \mathrm{~g}^{-1}$, the electrode modified by the nest-like $\mathrm{Si}$ nanospheres still showed a specific capacity of $1095 \mathrm{mAh} \mathrm{g}^{-1}$. Additionally, an excellent capacity retention was noted for the interconnected Si hollow nanospheres electrode (Figure 1) [11], synthesized via chemical vapor deposition (CVD) of Si on silica particles and then etching $\mathrm{SiO}_{2}$ by $\mathrm{HF}$. The asprepared hollow spherical structure was capable of delivering a high initial discharge capacity of $2725 \mathrm{mAh} \mathrm{g}^{-1}$ at a rate of $0.1 \mathrm{C}$ in the electrolyte of $1 \mathrm{~mol} / \mathrm{L} \mathrm{LiPF6}$ in a $1: 1(\mathrm{w} / \mathrm{w})$ EC/DEC mixture. Even after 700 cycles, the Si hollow sphere electrode still retained $1420 \mathrm{mAh} \mathrm{g}^{-1}$ at a rate of $0.5 \mathrm{C}$.

One-dimensional (1D) nanowires or nanotubes are also intriguing structures with good cycle stability. For example, $\mathrm{Si}$ nanowire electrode without binder, synthesized via the vapour-liquid-solid process on stainless steel substrates using $\mathrm{Au}$ catalyst, exhibited a reversible capacity of 3193
$\mathrm{mAh} \mathrm{g}^{-1}$ over 10 cycles at a $\mathrm{C} / 20$ rate in the electrolyte of 1 $\mathrm{mol} / \mathrm{L} \mathrm{LiPF}_{6}$ in a 1:1 (w/w) EC/DEC mixture [12]. Array of sealed $\mathrm{Si}$ nanotubes (Si NT), prepared by CVD of Si onto $\mathrm{ZnO}$ nanorods and selective removal of $\mathrm{ZnO}$ (Figure 2), showed 3360 and $1490 \mathrm{mAh} \mathrm{g}^{-1}$ of charge capacity at rates of 0.05 and $0.2 \mathrm{C}$ respectively in the electrolyte of 1.3 $\mathrm{mol} / \mathrm{L} \mathrm{LiPF}_{6}$ in EC/DEC (3:7 in volume). The capacity retentions after 50 cycles are about $81 \%$ and $82 \%$ at 0.05 and $0.2 \mathrm{C}$, respectively [13]. Possibly, 1D nanostructures might undergo facile strain relaxation and expand freely to accommodate the volume change during cycles.

Two-dimensional (2D) Si thin film is another promising nanostructure with improved cycle stability and rate capabilities. Basically, nanosized thin film can minimize the volume variation and retain structural integrity. The cycling stability and the Li accommodation capacity mainly depend on the film thickness as thinner films deliver larger accommodation capacity. A $50 \mathrm{~nm}$-thick Si film prepared from $n$-type $\mathrm{Si}$ was found to deliver a charge capacity over 3500 $\mathrm{mA} \mathrm{h} \mathrm{g}{ }^{-1}$ and maintained during 200 cycles at a rate of $2 \mathrm{C}$, while a $150 \mathrm{~nm}$-thick film showed around $2200 \mathrm{mAh} \mathrm{g}^{-1}$ during 200 cycles at $1 \mathrm{C}$ in the electrolyte of $1 \mathrm{~mol} / \mathrm{L} \mathrm{LiClO}_{4}$ in PC [14]. Although Si thin films offer high specific capacity, good capacity retention and fast charge/discharge rate, the practical application is hampered because of their
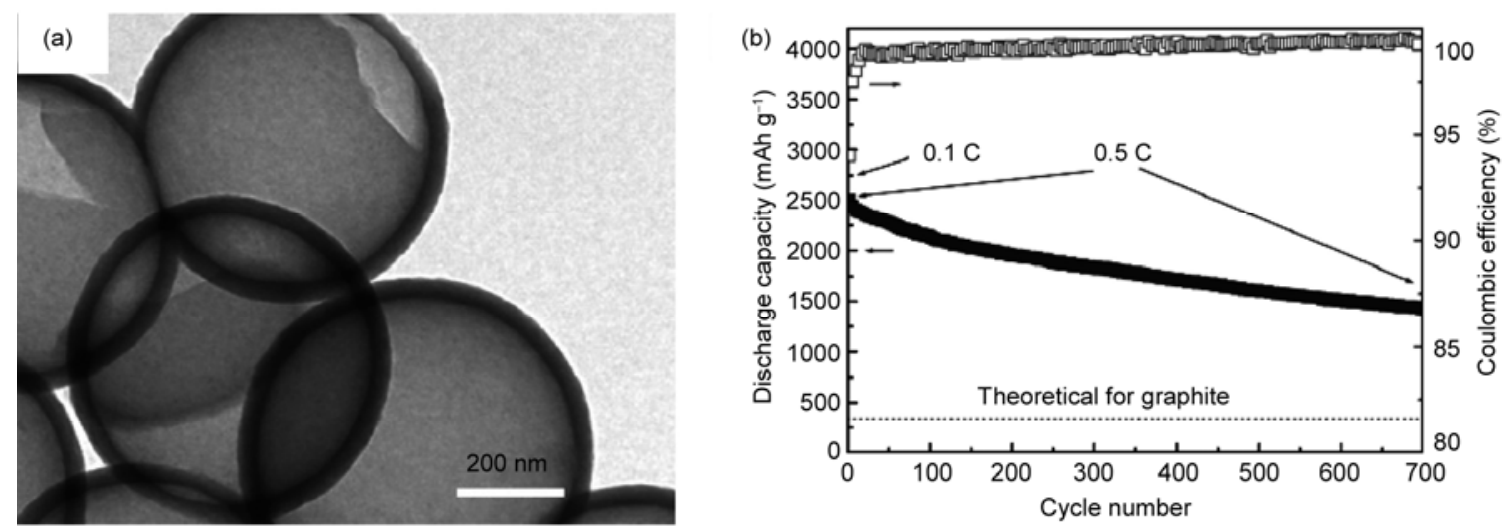

Figure 1 (a) TEM image and (b) reversible Li discharge capacity and Coulombic efficiency versus cycle number of interconnected hollow Si spheres. Reprinted with permission from [11]. Copyright (2011) American Chemical Society.
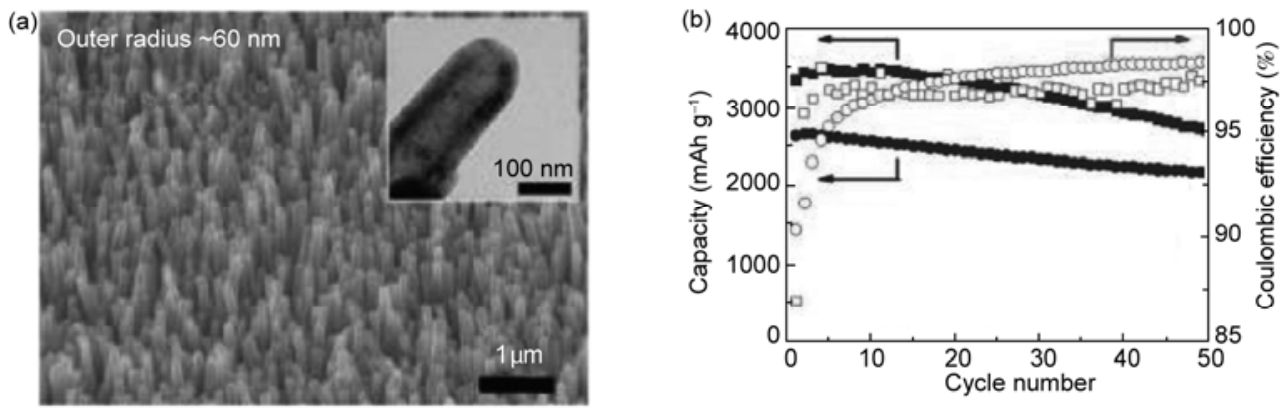

Figure 2 (a) SEM image (insets showing high magnification TEM images of the sealed tip of a Si NT) and (b) cycle performances at a rate of 0.05 and 0.2 C (square: 0.05 C, circle: 0.2 C) of a vertically aligned Si NT array. Reprinted with permission from [13]. Copyright (2010) American Chemical Society. 
prohibitively high synthesis costs for industry and low active material content.

\section{$2 \mathrm{Si} /$ metal composites}

In comparison with bulk $\mathrm{Si}$ materials, the pristine nanostructures of Si have shown improved capacity retention. However, the greatest disadvantage of the pristine nanostructures with high surface areas may lead to the risk of excessive side-reactions with the electrolyte [6]. Furthermore, the pristine nanosized Si anode materials are still plagued with the intrinsic low electrical conductivity of Si. Various studies have demonstrated that utilization of Si-based nanocomposites can circumvent the limitations of pure Si nanomaterials. In this context, metal with good electronic conductivity is one appealing candidate to cooperate with $\mathrm{Si}$ for improving lithium storage properties, especially rate capabilities.

Ag-coated three-dimensional (3D) macroporous $\mathrm{Si}$ has been constructed, in which Ag nanoparticles formed an interconnected conductive network, providing electron path- ways from the current collector to the whole surface area of the $3 \mathrm{D}$ porous $\mathrm{Si}$ particles. The $\mathrm{Ag}$-coated $3 \mathrm{D}$ macroporous $\mathrm{Si}$ delivered not only a reversible capacity of $1163 \mathrm{mAh} \mathrm{g}^{-1}$ at a rate of $0.2 \mathrm{C}$ after 100 cycles (Figure 3), but an enhanced rate capability of $1930 \mathrm{mAh} \mathrm{g}^{-1}$ at a rate of $1 \mathrm{C}$ in the electrolyte of $1 \mathrm{~mol} / \mathrm{L} \mathrm{LiPF}_{6}$ in dimethyl carbonate (DMC)/EC (1:1 in volume) containing 2 wt $\%$ vinylene carbonate (VC) [15].

In addition to the electrochemical active silver toward lithium storage, electrochemical inactive metal silicides with good conductivity also favor the effective charge transport. Si/TiSi ${ }_{2}$ heterostructures (Figure 4), consisting of $\mathrm{TiSi}_{2}$ nanonets coated with $\mathrm{Si}$ nanoparticles, displayed above $99 \%$ capacity retention per cycle at the level of $>1000 \mathrm{mAh} \mathrm{g}^{-1}$ over 100 cycles under a charging current density of $8400 \mathrm{~mA} \mathrm{~g}^{-1}$ in the electrolyte of $1 \mathrm{~mol} / \mathrm{L} \mathrm{LiPF}_{6}$ in EC/DEC (1:1 in volume) [16]. The excellent performance was attributed to the highly conductive $\mathrm{TiSi}_{2}$ nanonets used as the structural support. Another typical metal silicide, $\mathrm{Cu}_{3} \mathrm{Si}$, as reported recently by our laboratory, was in situ formed on the surface of $\mathrm{Si}$ nanoparticles by annealing $\mathrm{Si} /$ copper alginate microspheres in an inert atmosphere. The
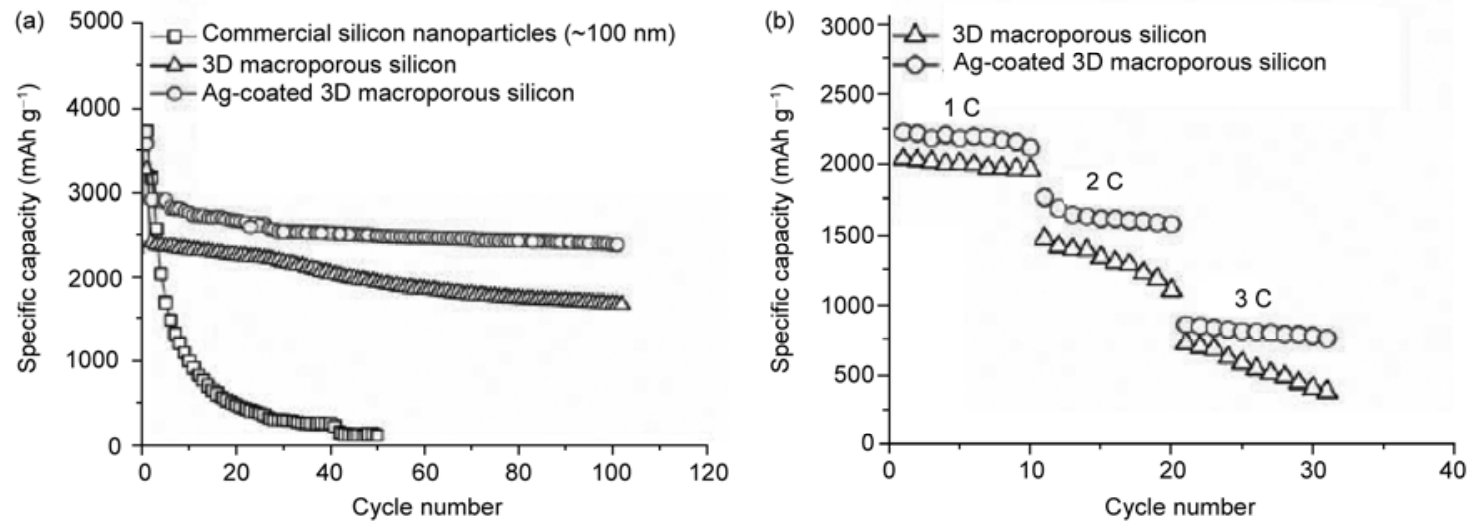

Figure 3 (a) Cyclability of 3D macroporous Si, Ag-coated 3D macroporous Si, and commercial Si nanoparticles; (b) rate capabilities of 3D macroporous $\mathrm{Si}$ and a Ag coated 3D macroporous Si electrode. The current densities are indicated in (b). All of them were tested at a rate of $0.2 \mathrm{C}$ in a voltage range of 5 $\mathrm{mV}-1.0 \mathrm{~V}$. Reprinted with permission from [15].
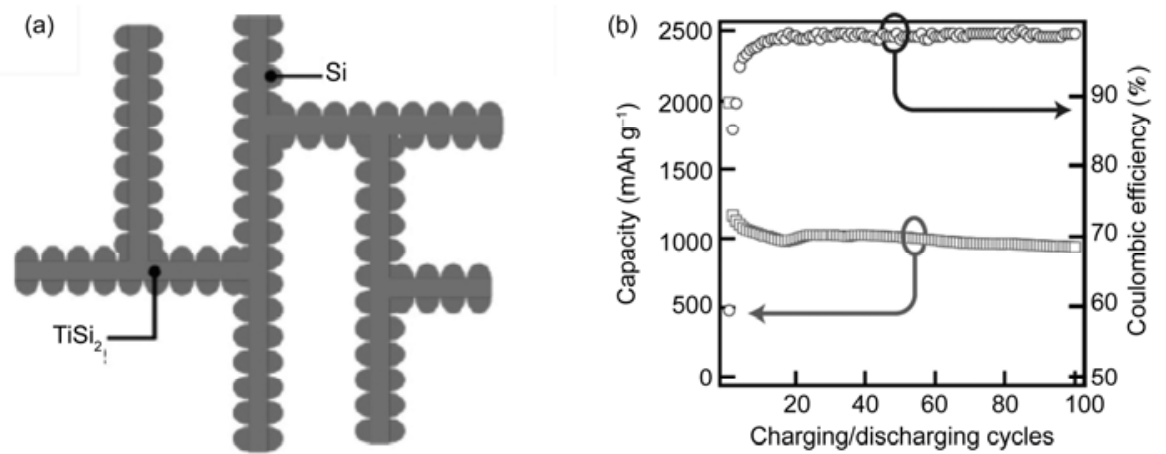

Figure 4 (a) Schematic and (b) charge capacity and Coulombic efficiency under a current density of $8400 \mathrm{~mA} \mathrm{~g}^{-1}$ between $0.15-3.00 \mathrm{~V}$ of the $\mathrm{Si} / \mathrm{TiSi}_{2}$ heteronanostructure. Reprinted with permission from [16]. Copyright (2010) American Chemical Society. 
utilization of $\mathrm{Cu}_{3} \mathrm{Si}$ endowed the resulting $\mathrm{Si} / \mathrm{C}$ nanoporous microspheres with enhanced cycling performance and rate performance compared with Si nanoparticles [17]. Aside from the improvement of conductivity for $\mathrm{Si} /$ metal nanocomposites, inactive metal oxides coating was utilized to form stable SEI on the surface of electrode materials in the common electrolyte of $\mathrm{LiPF}_{6}$. An elegant $\mathrm{Cu}-\mathrm{Si}$ nanocable array (Figure 5) was prepared firstly from the growth of $\mathrm{CuO}$ nanowire arrays by heating a copper current collectors in oxygen atmosphere. Then the $\mathrm{CuO}$ nanowire arrays were coated with $\mathrm{Si}$ and $\mathrm{Al}_{2} \mathrm{O}_{3}$ step by step, and subsequently annealed in reduced atmosphere [18]. The $\mathrm{Cu}-\mathrm{Si}-\mathrm{Al}_{2} \mathrm{O}_{3}$ nanocables exhibited a specific capacity of about 1560 $\mathrm{mAh} \mathrm{g} \mathrm{g}^{-1}$ after 100 cycles under a current density of 1400 $\mathrm{mA} \mathrm{g}^{-1}$ in the electrolyte of $1 \mathrm{~mol} / \mathrm{L} \mathrm{LiPF}_{6}$ in a mixture of EC/DMC/DEC (1:1:1 wt\%) plus $2 \mathrm{wt} \%$ VC. Furthermore, the nanocables displayed a specific capacity of 1490 and $1140 \mathrm{mAh} \mathrm{g}^{-1}$ as increasing the current density to 2800 and $7000 \mathrm{~mA} \mathrm{~g}^{-1}$, respectively. The remarkably high rate capability mainly benefits from the unique configuration of nanocables with excellent ionic-electronic conductivity [19-21]. The attractive structure of $\mathrm{Cu}-\mathrm{Si}_{-}-\mathrm{Al}_{2} \mathrm{O}_{3}$ nanocables enabled lithium ion to diffuse readily into $\mathrm{Si}$ nanolayer from the outside liquid electrolyte. The copper core inside acts as the continuous electron diffusion pathway and thereby allows for fast electron transport in the electrode. In addition, the $\mathrm{Al}_{2} \mathrm{O}_{3}$ coating layer on $\mathrm{Si}$ surface serves as a thin and stable surface and thereby facilitates the formation of stable SEI layer in the common electrolyte of $\mathrm{LiPF}_{6}$ upon cycling.

\section{Si/C composites}

Concerning graphite, the commercial anode material, tremendous studies have focused on carbonaceous materials, owing to their unique characteristics (relative softness, small volume change during Li insertion/extraction, good electronic conductivity, and the moderate SEI formation). Incorporation of $\mathrm{Si} / \mathrm{C}$ nanocomposites represents one attractive route to conquer the intrinsic drawbacks of $\mathrm{Si}$.

Highly conductive carbon (such as graphite) was utilized to load Si nanoparticles by ball milling and subsequently coated with amorphous carbon, in which Si nanoparticles were embedded into a relatively dense carbon matrix [22-25]. The as-prepared $\mathrm{Si} / \mathrm{C}$ nanocomposites only showed limited enhancements of cycle stability and capacity because the dense carbon matrix could accommodate the volume changes only to a limited degree.

Carbon nanotubes (CNTs) and graphene nanosheets have been widely investigated as conductive substrates to facilitate charge transport, flexibility and mechanical strength to
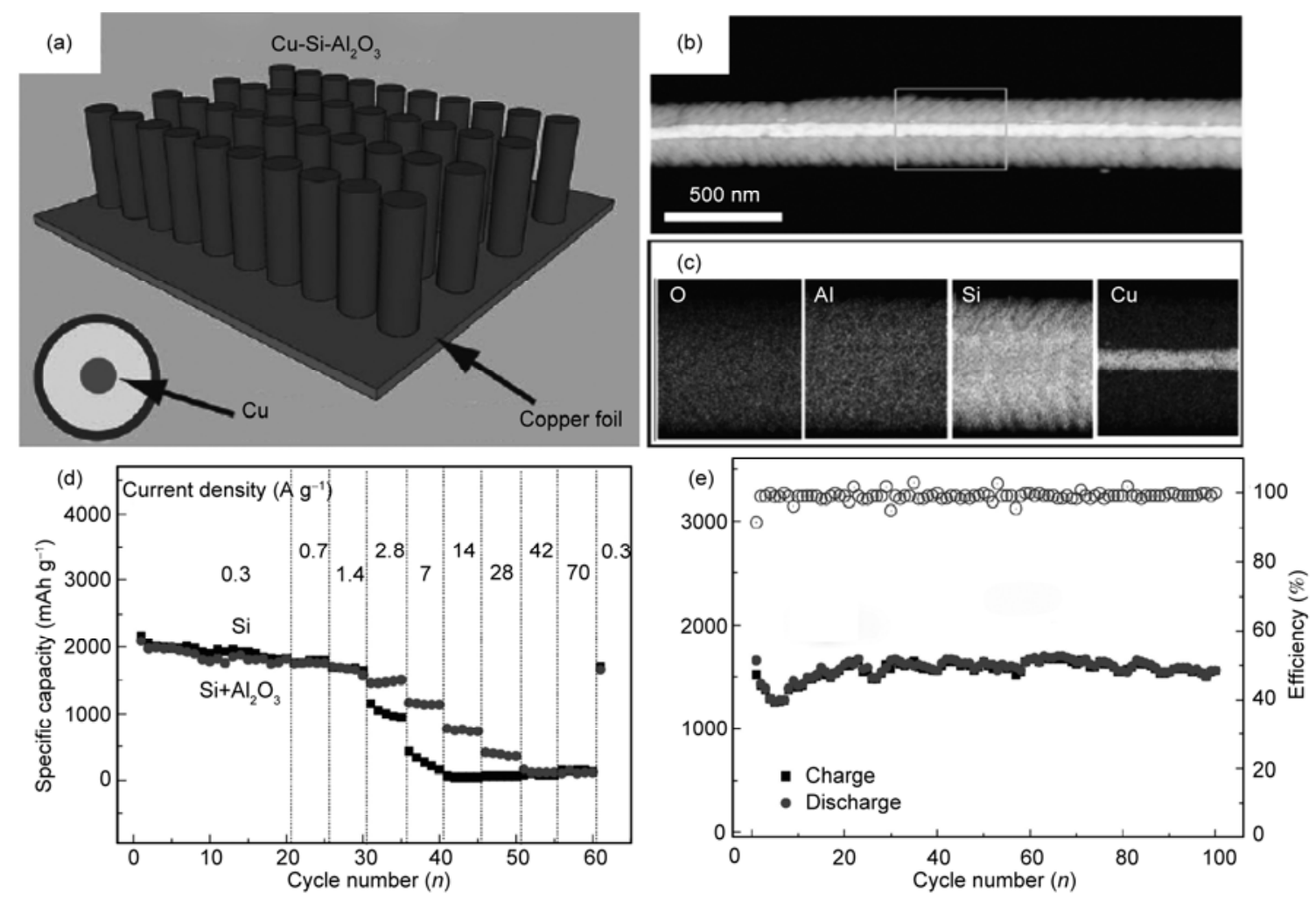

Figure 5 (a) Schematic; (b) annual dark-field TEM image and (c) corresponding EDX elemental mappings of $\mathrm{O}, \mathrm{Al}, \mathrm{Si}$, and $\mathrm{Cu}$ for the $\mathrm{Cu}-\mathrm{Si}$ - $\mathrm{Al}{ }_{2} \mathrm{O}_{3}$ nanocables; (d) comparison of the rate capabilities of $\mathrm{Cu}-\mathrm{Si}_{-}-\mathrm{Al}_{2} \mathrm{O}_{3}$ nanocables and $\mathrm{Cu}-\mathrm{Si}$ cycled under different current densities; (e) cycling behavior under a current density of $1400 \mathrm{~mA} \mathrm{~g}^{-1}$ of $\mathrm{Cu}-\mathrm{Si}_{-} \mathrm{Al}_{2} \mathrm{O}_{3}$ nanocables. Voltage limits are between 0 and $2 \mathrm{~V}$ (vs. $\mathrm{Li}^{+} / \mathrm{Li}$ ). $\mathrm{Reprinted} \mathrm{with} \mathrm{permission} \mathrm{from} \mathrm{[18].}$ 
accommodate the volume change of active electrode materials during cycles. The resulted $\mathrm{Si} / \mathrm{CNTs}$ and $\mathrm{Si} /$ graphene nanocomposites could exhibit good cycle stability and rate performances. In this aspect, Si/CNT nanocomposites with enhanced properties were prepared either via depositing $\mathrm{Si}$ nanoparticles on the surface of CNTs [26] or CNTs' film [27-29], or via growing CNTs directly on the surface of Si nanoparticles [30]. Additionally, Si/graphene composite [31,32], including $\mathrm{Si}$ nanoparticles highly dispersed between graphene nanosheets via freez-drying [32], showed a reversible specific capacity above $1153 \mathrm{~mA} \mathrm{~h} \mathrm{~g}^{-1}$ after 100 cycles in the elelctroylte of $1 \mathrm{~mol} / \mathrm{L} \mathrm{LiPF}_{6}$ in a mixture of EC/DMC/DEC (1:1:1 wt\%) containing $2 \mathrm{wt} \%$ VC. Note that it is vital to uniformly disperse $\mathrm{Si}$ nanoparticles in CNTs or grapheme nanosheets to sustain good cycle stability. The well-dispersed Si nanoparticles were actually prevented from agglomeration into even larger particles, which are considered to be more vulnerable to fracture and pulverization during cycling.

In addition to the utilization of conductive carbonaceous materials to combine with $\mathrm{Si}$, core/shell structure with $\mathrm{Si}$ core were utilized for the formation of stable SEI via pyrolysis of organic precursors [33-36]. For example, Si nanoparticles were coated with carbon by the hydrothermal carbonization of glucose to obtain $\mathrm{Si}_{\mathrm{SiO}_{x}} / \mathrm{C}$ nanocomposite [34]. The reversible capacity of $\mathrm{Si}_{0} \mathrm{SiO}_{x} / \mathrm{C}$ nanocomposite was as high as $1100 \mathrm{mAh} \mathrm{g}^{-1}$ under a current density of 150 $\mathrm{mA} \mathrm{g}^{-1}$ with no further decay of capacity even after $60 \mathrm{cy}-$ cles in the electrolyte of $1 \mathrm{~mol} / \mathrm{L} \mathrm{LiPF} 6$ in EC/DMC (1:1, $\mathrm{v} / \mathrm{v})$ containing $2 \mathrm{wt} \% \mathrm{VC}$.

Porous configuration of $\mathrm{Si} / \mathrm{C}$ anode materials was confirmed to be a viable solution due to accommodating the large volume changes of $\mathrm{Si}$ during cycles, although the volumetric energy density of porous materials was lower than that of dense materials. Porous Si particles with tiny walls were prepared by annealing and etching of physical composites obtained from butyl-capped $\mathrm{Si}$ gels and $\mathrm{SiO}_{2}$ nanoparticles [37]. The porous $\mathrm{Si} / \mathrm{C}$ composite with a highly porous and interconnected structure, showed a reversible capacity of about $2500 \mathrm{mAh} \mathrm{g}^{-1}$ at a $1 \mathrm{C}$ rate after $100 \mathrm{cy}$ cles due to its better accommodation of large strains without pulverization during cycles in the electrolyte of $1 \mathrm{~mol} / \mathrm{L}$
$\mathrm{LiPF}_{6}$ in a EC/DEC/ethyl-methyl carbonate (EMC) mixture (30:30:40 vol\%) (Figure 6). Furthermore, Coulombic efficiencies of the porous $\mathrm{Si} / \mathrm{C}$ particles at both $0.2 \mathrm{C}$ and $1 \mathrm{C}$ rates were higher than $98 \%$. The good rate capability can be attributed to the interconnected 3D porous structure that provides fast lithium-ion mobility, and the improved efficiency may be associated with the carbon coating layer, which decreases the occurrence of side reactions with the electrolyte.

Similar to the role of porous Si framework, Si/C spherical granules with spherical carbon black scaffold was reported with impressive lithium storage properties [38]. Annealed carbon black scaffold were coated with Si nanoparticles and carbon respectively to assemble the porous $\mathrm{Si} / \mathrm{C}$ granules, which exhibited the specific capacity above 1500 $\mathrm{mA} \mathrm{h} \mathrm{g}{ }^{-1}$ at the fast discharge rate of $1 \mathrm{C}$ after 100 cycles in the electrolyte of $1 \mathrm{~mol} / \mathrm{L} \mathrm{LiPF}_{6}$ in an EC/DEC/DMC/VC mixture (Figure 7). Highly conductive porous carbon framework provides a mechanical support for Si nanoparticles and an electrical conducting pathway to lithium ion and electrons. Also, the carbon deposited on Si nanoparticles could facilitate the formation of a stable SEI on the surface of $\mathrm{Si}$ nanoparticles and prevent the agglomeration of tiny $\mathrm{Si}$ nanoparticles.

\section{Perspective}

In this review, we have focused on the improvements on $\mathrm{Si}$ based anode materials in terms of morphology and structure design, i.e. diverse $\mathrm{Si}$ nanostructures, $\mathrm{Si} /$ metal nanocomposites, and $\mathrm{Si} / \mathrm{C}$ nanocomposites. Either designing diverse pristine $\mathrm{Si}$ nanostructures, or hybridizing $\mathrm{Si} / \mathrm{metal}$ and $\mathrm{Si} / \mathrm{C}$ nanocomposites can significantly improve the lithium storage properties of Si-based materials. As shown from previous studies, fascinating cyclic stability and high rate capabilities could be achieved when the Si-based materials have the following structure features: (1) Nanoporous structure to accommodate the volume variation during cycling; (2) fast electron conducting pathways to improve the poor electrical conductivity of $\mathrm{Si}$; and (3) stable surface coating to form stable and thin SEI layer on the surface of Si.
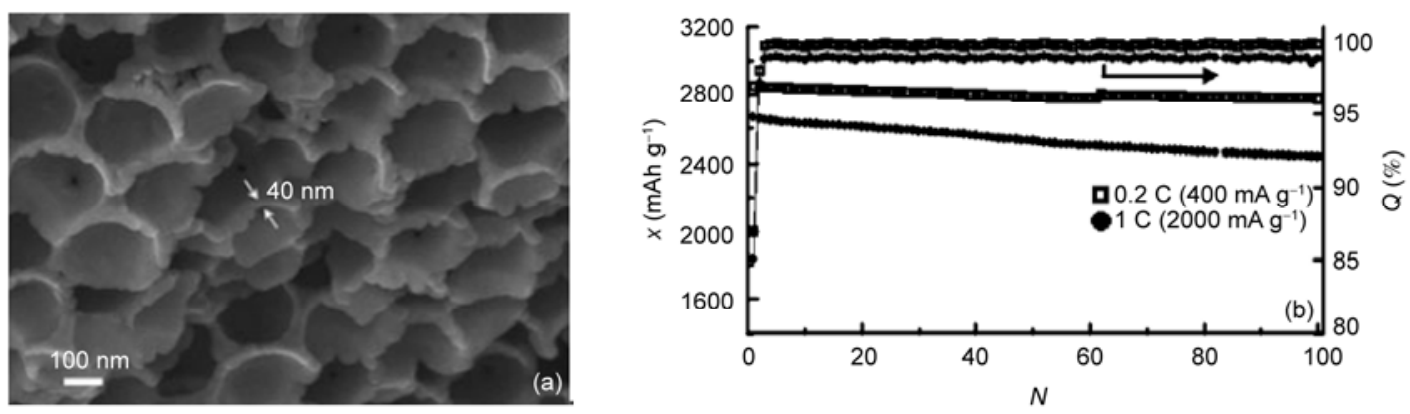

Figure 6 (a) SEM image and (b) plot of charge capacities versus cycle number of the 3D porous Si particles cycled at different rates $(0.2$ and $1 \mathrm{C})$ between 0 and 1.5 V. $x=$ charge capacity, $N=$ cycle number, $Q=$ Coulombic efficiency. Reprinted with permission from [37]. 
(a)
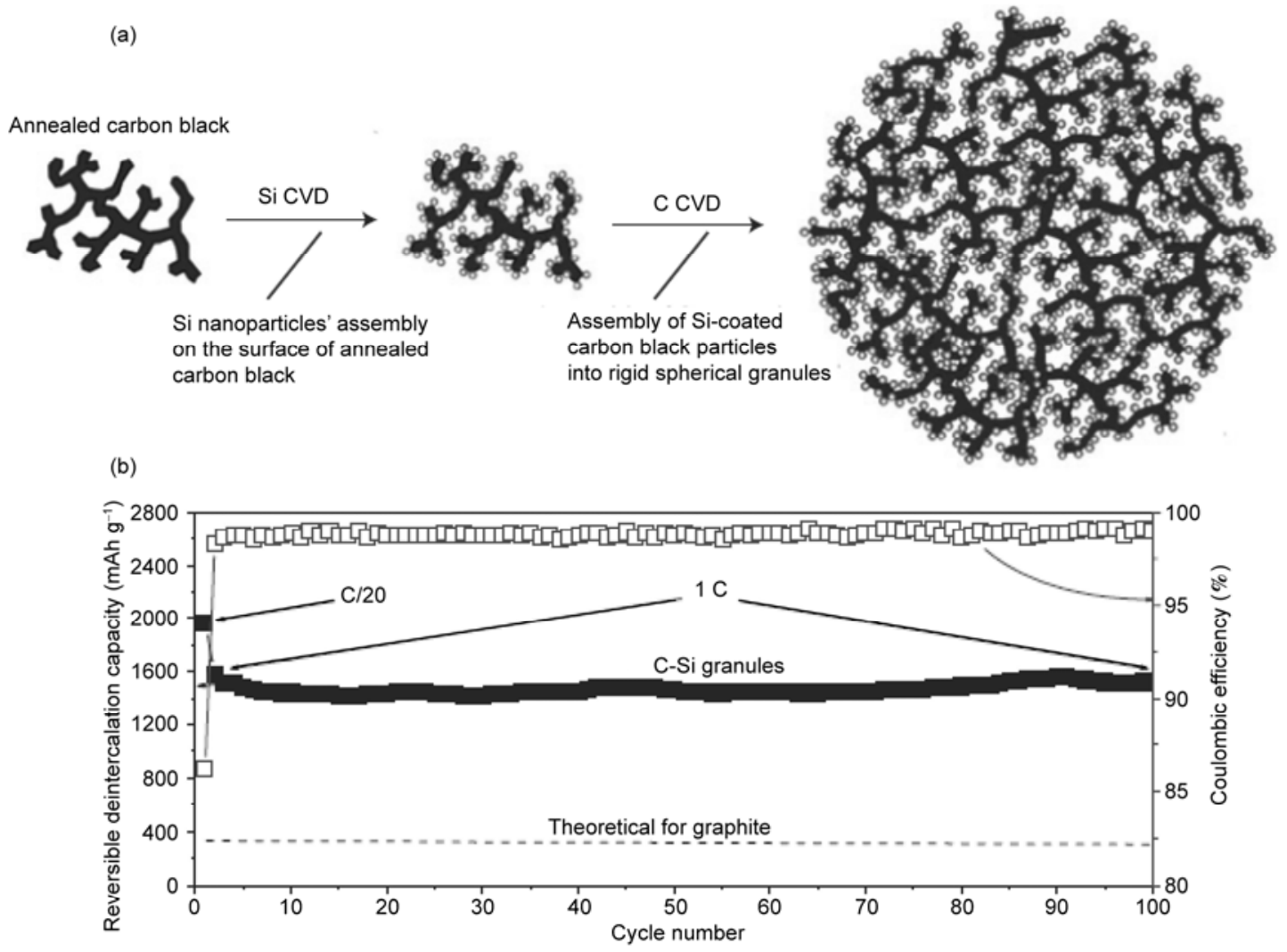

Figure 7 (a) Schematic formation of Si-C nanocomposite granule and (b) reversible Li deintercalation capacity and Coulombic efficiency of the Si-C granule electrode versus cycle number. Reprinted with permission from [38].

Although considerable advances have been achieved in the last decade to design and synthesize Si-based anode materials, some perspectives could focus on electrolytes and binders, greatly influencing the electrochemical performances of Si-based anode materials as mentioned in recent research. For nanostructured Si anode materials, the commonly used $\mathrm{LiPF}_{6}$ electrolyte decomposes gradually and produces $\mathrm{HF}$, which can etch $\mathrm{Si}$. Additionally, the stable SEI film on the surface of Si is difficult to form owing to repeatedly huge volume change during cycling and the unstable nature of the surface of nanosized Si. As a result, nanostructured $\mathrm{Si}$ anode materials exhibited a large irreversible capacity loss (i.e. low Coulombic efficiency) and short cycle life. Except for the stable coating layer on the surface of $\mathrm{Si}[18,39]$, the electrolyte containing VC with 1 $\mathrm{mol} / \mathrm{L} \mathrm{LiPF}_{6}$ in $\mathrm{EC} / \mathrm{DMC}$ solution has been recognized to favor the formation of stable SEI [34]. Furthermore, sodium alginate, polyacrylic acid and sodium carboxymethylcellulose with carboxyl groups are potential binders for Sibased electrodes compared with the commonly used poly (vinylidene fluoride) for Si-based electrode materials [40-43]. Particularly, sodium alginate can assist in building a deformable and stable SEI film on the surface of Si, clarifying that it is vital to use a suitable binder to enhance the lithium storage for Si-based anode materials. Achieving
Si-based anode materials with good cycle stability and high specific capacity require the inputs of multiple disciplines, which challenges the design of new structures, reveal more suitable electrolytes and binders to assemble the next generation LIBs with high-energy densities and long cycle life.

This work was supported by the National Basic Research Program of China (2011CB935700 and 2012CB932900), the National Natural Science Foundation of China (91127044 and 21073205), and the Chinese Academy of Sciences.

1 Aricò A S, Bruce P G, Scrosati B, et al. Nanostructured materials for advanced energy conversion and storage devices. Nat Mater, 2005, 4: 366-377

2 Wu X L, Jiang L Y, Cao F F, et al. $\mathrm{LiFePO}_{4}$ nanoparticles embedded in a nanoporous carbon matrix: Superior cathode material for electrochemical energy-storage devices. Adv Mater, 2009, 21: 2710-2714

3 Yuan L X, Wang Z H, Zhang W X, et al. Development and challenges of $\mathrm{LiFePO}_{4}$ cathode material for lithium-ion batteries. Energy Environ Sci, 2011, 4: 269-284

4 Zhang W M, Hu J S, Guo Y G, et al. Tin-nanoparticles encapsulated in elastic hollow carbon spheres for high-performance anode material in lithium-ion batteries. Adv Mater, 2008, 20: 1160-1165

5 Xin S, Guo Y G, Wan L J. Electrode materials for lithium secondary batteries with high energy densities (in Chinese). Sci China Chim, 2011, 41: 1229-1239

6 Guo Y G, Hu J S, Wan L J. Nanostructured materials for electrochemical energy conversion and storage devices. Adv Mater, 2008, 
20: $2878-2887$

7 Li H, Wang Z X, Chen L Q, et al. Research on advanced materials for Li-ion batteries. Adv Mater, 2009, 21: 4593-4607

8 Huggins R A. Lithium alloy negative electrodes. J Power Sources, 1999, 81: 13-19

9 Li H, Huang X, Chen L Q, et al. A high capacity nano-Si composite anode material for lithium rechargeable batteries. Electrochem Solid-State Lett, 1999, 2: 547-549

$10 \mathrm{Ma} \mathrm{H}$, Cheng F, Chen J, et al. Nest-like silicon nanospheres for high-capacity lithium storage. Adv Mater, 2007, 19: 4067-4070

11 Yao Y, McDowell M T, Ryu I, et al. Interconnected silicon hollow nanospheres for lithium-ion battery anodes with long cycle life. Nano Lett, 2011, 11: 2949-2954

12 Chan C K, Peng H, Liu G, et al. High-performance lithium battery anodes using silicon nanowires. Nat Nanotechnol, 2008, 3: 31-35

13 Song T, Xia J, Lee J H, et al. Arrays of sealed silicon nanotubes as anodes for Lithium ion batteries. Nano Lett, 2010, 10: 1710-1716

14 Ohara S, Suzuki J, Sekine K, et al. A thin film silicon anode for Li-ion batteries having a very large specific capacity and long cycle life. J Power Sources, 2004, 136: 303-306

$15 \mathrm{Yu} \mathrm{Y,} \mathrm{Gu} \mathrm{L,} \mathrm{Zhu} \mathrm{C,} \mathrm{et} \mathrm{al.} \mathrm{Reversible} \mathrm{storage} \mathrm{of} \mathrm{lithium} \mathrm{in} \mathrm{sil-}$ ver-coated three-dimensional macroporous silicon. Adv Mater, 2010, 22: $2247-2250$

16 Zhou S, Liu X, Wang D. Si/TiSi 2 heteronanostructures as highcapacity anode material for $\mathrm{Li}$ ion batteries. Nano Lett, 2010, 10: 860-863

17 Yin Y X, Xin S, Wan L J, et al. Electrospray synthesis of silicon/carbon nanoporous microspheres as improved anode materials for lithium-ion batteries. J Phys Chem C, 2011, 115: 14148-14154

18 Cao F F, Deng J W, Xin S, et al. Cu-Si nanocable arrays as high-rate anode materials for lithium-ion batteries. Adv Mater, 2011, 23: $4415-4420$

19 Cao F F, Guo Y G, Zheng S F, et al. Symbiotic coaxial nanocables: Facile synthesis and an efficient and elegant morphological solution to the lithium storage problem. Chem Mater, 2010, 22: 1908-1914

20 Cao F F, Xin S, Guo Y G, et al. Wet chemical synthesis of $\mathrm{Cu} / \mathrm{TiO}_{2}$ nanocomposites with integrated nano-current-collectors as high-rate anode materials in lithium-ion batteries. Phys Chem Chem Phys, 2011, 13: 2014-2020

21 Cao F F, Guo Y G, Wan L J. Better lithium-ion batteries with nanocable-like electrode materials. Energy Environ Sci, 2011, 4: 1634-1642

22 Dimov N, Kugino S, Yoshio M. Mixed silicon-graphite composites as anode material for lithium ion batteries: Influence of preparation conditions on the properties of the material. J Power Sources, 2004, 136: $108-114$

23 Fuchsbichlera B, Stangla C, Krenc H, et al. High capacity graphite-silicon composite anode material for lithium-ion batteries. J Power Sources, 2011, 196: 2889-2892

24 Lee J H, Kim W J, Kim J Y, et al. Spherical silicon/graphite/carbon composites as anode material for lithium-ion batteries. J Power Sources, 2008, 176: 353-358

25 Yoshio M, Tsumura T, Dimov N. Electrochemical behaviors of silicon based anode material. J Power Sources, 2005, 146: 10-14
26 Wang W, Kumta P N. Nanostructured hybrid silicon/carbon nanotube heterostructures: Reversible high-capacity lithium-ion anodes. ACS Nano, 2010, 4: 2233-2241

27 Shu J, Li H, Yang R Z, et al. Cage-like carbon nanotubes/Si composite as anode material for lithium ion batteries. Electrochem Commun, 2006, 8: 51-54

28 Cui L F, Hu L, Choi J W, et al. Light-weight frees standing carbon nanotube-silicon films for anodes of lithium ion batteries. ACS Nano, 2010, 4: 3671-3678

29 Chou S L, Zhao Y, Wang J Z, et al. Silicon/single-walled carbon nanotube composite paper as a flexible anode material for lithium ion batteries. J Phys Chem C, 2010, 114: 15862-15867

30 Gao P F, Nuli Y, He Y S, et al. Direct scattered growth of MWNT on $\mathrm{Si}$ for high performance anode material in Li-ion batteries. Chem Commun, 2010, 46: 9149-9151

31 Lee J K, Smith K B, Haynerb C M, et al. Silicon nanoparticles-graphene paper composites for $\mathrm{Li}$ ion battery anodes. Chem Commun, 2010, 46: 2025-2027

32 Zhou X S, Yin Y X, Wan L J, et al. Facile synthesis of silicon nanoparticles inserted in graphene sheets as improved anode materials for lithium-ion batteries. Chem Commun, 2012, 48: 2198-2200

$33 \mathrm{Ng} \mathrm{S} \mathrm{H}$, Wang J, Wexler D, et al. Highly reversible lithium storage in spheroidal carbon-coated silicon nanocomposites as anodes for lithium-ion batteries. Angew Chem Int Ed, 2006, 45: 6896-6899

$34 \mathrm{Hu}$ Y S, Demir-Cakan R, Titirici M M, et al. Superior storage performance of a $\mathrm{Si} @ \mathrm{SiO}_{x} / \mathrm{C}$ nanocomposite as anode material for lithium-ion batteries. Angew Chem Int Ed, 2008, 47: 1645-1649

35 Cakan R D, Titirici M M, Antonietti M, et al. Hydrothermal carbon spheres containing silicon nanoparticles: Synthesis and lithium storage performance. Chem Commun, 2008, 3759-3761

36 Hu Y S, Adelhelm P, Smarsly B M, et al. Highly stable lithium storage performance in a porous carbon/silicon nanocomposite. Chem Sus Chem, 2010, 3: 231-235

37 Kim H, Han B, Choo J, et al. Three-dimensional porous silicon particles for use in high-performance lithium secondary batteries. Angew Chem Int Ed, 2008, 47: 10151-10154

38 Magasinski A, Dixon P, Hertzberg B, et al. High-performance lithium-ion anodes using a hierarchical bottom-up approach. Nat Mater, 2010, 9: 353-359

39 He Y, Yu X Q, Wang Y H, et al. Alumina-coated patterned amorphous silicon as the anode for a lithium-ion battery with high coulombic efficiency. Adv Mater, 2011, 23: 4938-494

40 Kovalenko I, Zdyrko B, Magasinski A, et al. A major constituent of brown algae for use in high-capacity Li-ion batteries. Science, 2011, 7: 75-79

41 Buqa H, Holzapfel M, Krumeich F, et al. Study of styrene butadiene rubber and sodium methyl cellulose as binder for negative electrodes in lithium-ion batteries. J Power Sources, 2006, 161: 617-622

42 Magasinski A, Zdyrko B, Kovalenko I, et al. Toward efficient binders for Li-ion battery Si-based anodes: Polyacrylic acid. ACS Appl Mater Interfaces, 2010, 2: 3004-3010

43 Bridel J S, Azaïs T, Morcrette M, et al. Key parameters governing the reversibility of $\mathrm{Si} /$ carbon/CMC electrodes for Li-ion batteries. Chem Mater, 2010, 22: 1229-1241

Open Access This article is distributed under the terms of the Creative Commons Attribution License which permits any use, distribution, and reproduction in any medium, provided the original author(s) and source are credited. 